\title{
A self-adaptive two-parameter method for characterizing roughness of multi-scale subglacial topography
}

\section{Article}

*Present address: Polar Research Institute of China, 451 Jinqiao Road, Pudong, Shanghai 200136, China.

Cite this article: Lang S, Xu B, Cui X, Luo K, Guo J, Tang X, Cai Y, Sun B, Siegert MJ (2021). A self-adaptive two-parameter method for characterizing roughness of multi-scale subglacial topography. Journal of Glaciology 67(263), 560-568. https://doi.org/10.1017/ jog.2021.12

Received: 11 August 2020

Revised: 25 January 2021

Accepted: 26 January 2021

First published online: 24 February 2021

Keywords:

Antarctic glaciology; glaciological instruments and methods; radio-echo sounding

\section{Author for correspondence:}

Xiangbin Cui,

E-mail: cuixiangbin@pric.org.cn

\section{Shinan Lang ${ }^{1}$, Ben $\mathrm{Xu}^{1,2}\left(\mathbb{D}\right.$, Xiangbin $\mathrm{Cui}^{2 *}(\mathbb{D})$, Kun $\mathrm{Luo}^{2}$, Jingxue Guo ${ }^{2}$ (D), Xueyuan Tang ${ }^{2}$, Yiheng $\mathrm{Cai}^{1}$, Bo Sun ${ }^{2}$ and Martin J. Siegert ${ }^{3}$ (D)}

${ }^{1}$ Faculty of Information Technology, Beijing University of Technology, Beijing 100124, China; ${ }^{2}$ Polar Research Institute of China, 451 Jinqiao Road, Pudong, Shanghai 200136, China and ${ }^{3}$ Grantham Institute and Department of Earth Science and Engineering, Imperial College London, South Kensington, London, UK

\section{Abstract}

During the last few decades, bed-elevation profiles from radar sounders have been used to quantify bed roughness. Various methods have been employed, such as the 'two-parameter' technique that considers vertical and slope irregularities in topography, but they struggle to incorporate roughness at multiple spatial scales leading to a breakdown in their depiction of bed roughness where the relief is most complex. In this article, we describe a new algorithm, analogous to wavelet transformations, to quantify the bed roughness at multiple scales. The 'Self-Adaptive TwoParameter' system calculates the roughness of a bed profile using a frequency-domain method, allowing the extraction of three characteristic factors: (1) slope, (2) skewness and (3) coefficient of variation. The multi-scale roughness is derived by weighted-summing of these frequencyrelated factors. We use idealized bed elevations to initially validate the algorithm, and then actual bed-elevation data are used to compare the new roughness index with other methods. We show the new technique is an effective tool for quantifying bed roughness from radar data, paving the way for improved continental-wide depictions of bed roughness and incorporation of this information into ice flow models.

\section{Introduction}

The mechanical flow of ice is a product of the balance between the gravitational driving force that acts to move ice downstream and the resistive forces that counter this motion (Paterson, 1994). This counter force is influenced by the nature of the bed, such as thermal regime, material properties of the bed and roughness of the ice-bed interface. The quantitative description of subglacial topography is therefore important to understanding glacial dynamics (Hubbard and Hubbard, 1998; Taylor and others, 2004; Rippin and others, 2006), which is in meter scale roughness that relates to the basal sliding. Theories suggest that ice dynamics (particularly basal flow) are directly related to bed roughness at a range of spatial scales (Paterson, 1994; Joughin and others, 1998; Schoof, 2002), and this is increasingly regarded as an important research area in glaciology (Cooper and others, 2019). Li and others (2010) showed that bed roughness derived from a frequency domain method applied to ice-penetrating radar data can be used to deduce the formation (marine or continental) and erosion history of a variety of end-case landscapes. Recently, bed roughness has also been used to simulate realistic digital elevation models and to locate subglacial lakes (e.g. Mackie and others, 2020; Goff and others, 2014). Clearly, a method that allows bed roughness to be extracted from radar data accurately and efficiently, with maximum information incorporated within the results, would allow it to become better assimilated into assessments of ice dynamics, glacial history and basal conditions (Eisen and others, 2020).

The main methods of quantifying bed roughness from radar data can be divided into two categories: the electromagnetic scattering properties of the bed-echo waveform; and the statistical properties of the along-track topography (Cooper and others, 2019; Eisen and others, 2020).

Analysis of electromagnetic scattering properties involves (1) waveform analysis (e.g. Cooper and others, 2019), (2) analysis of distribution of peak bed-echo power due to scattering loss (e.g. Grima and others, 2014), and (3) specularity analysis using different synthetic aperture sizes (e.g. Schroeder and others, 2013). Both theoretical predictions and observations demonstrate that specular reflections are suppressed in rougher regions (Jordan and others, 2017).

Methods that use statistical properties can be divided into those utilizing the 'space domain' and 'frequency domain'. Space domain methods include some form of functional parameterization, such as the extraction of root-mean-square (rms) height, rms deviation, rms slope and autocorrelation length (Shepard and others, 2001; MacGregor and others, 2013), from which variograms ( $\mathrm{rms}$ height versus profile length) and deviograms ( $\mathrm{rms}$ deviation versus horizontal lag) can be constructed, which have been well applied to glacier beds (MacGregor and others, 2013; Jordan and others, 2017). In these methods, bed-roughness results vary with the lengths of the quantified profile or the spatial lag, often following a power-law trend with these lengths 
(Shepard and others, 2001). In the frequency domain, Hubbard and others (2000) and Taylor and others (2004) defined a singleparameter roughness index as the integral of the spectrum within a specified interval, which can be used to extract the so-called 'Hurst exponent' (Martinez and others, 2013) and the corner wavenumber. This single-parameter roughness index has two flaws, however: (1) it cannot be used directly to quantify slope bed irregularities, which leads to topography with different slope irregularities having similar roughness indices; and (2) it requires a fixed-size moving window (MW), which limits the scale of roughness quantified. Addressing the first issue, $\mathrm{Li}$ and others (2010) designed a two-parameter roughness quantization method, which we call 'the previous two-parameter method' in this paper, that incorporates both vertical change and slope changes. However, this method is still problematic as it requires a fixed-size MW. The outcome is that large-scale roughness results do not incorporate small-scale terrain undulations, and vice versa. To solve this problem, the 'wavelet transform' method was developed. This technique uses different scales of MW, which means a variable-size MW, to divide the roughness signal at each position into components related to scale; the wavelet coefficients are the weight of each component (Boggess and Narcowich, 2015). Our method uses a range of scales like the wavelet transform method rather than a single-scale like the previous fast Fourier transform (FFT) methods.

Self-affine roughness (Jordan and others, 2017) is represented by the 'Hurst exponent' as a multi-scale roughness parameter that can accommodate a span of scales to a certain extent. In this method, problems occur in relation to 'breakpoints', however, where a power law appears to 'break over' and obey a different power law. This requires the investigator to subjectively choose where the beginning and endpoints of each trend occur when a breakpoint is evident (Shepard and others, 2001). Besides that, the 'Hurst exponent' results show rapid local fluctuations on maps (Jordan and others, 2017; Eisen and others, 2020), which make it difficult to quantify the large span of terrains.

In this article, we describe a new algorithm to quantify bed roughness, improving the previous two-parameter method ( $\mathrm{Li}$ and others, 2010) by accounting for different scales of roughness through a self-adaptive approach. In addition, the 'scale' we use in this paper is the horizontal length of the bed elevation profile which is quantified as roughness. In other words, the 'scale' in our method means the horizontal length of the FFT MW and the 'scale' in rms height method means the horizontal length of the quantified profile.

\section{Methods}

\subsection{Outline and flowchart of the method}

To solve the scale problem of the previous two-parameter method, we propose a self-adaptive two-parameter roughness quantization technique in four steps, as described in Figure 1.

\subsection{Step 1: selecting the range of scale}

Our two-parameter roughness method, and the extraction of the characteristic factors, requires a bed elevation profile with a fixed sampling interval. It is therefore necessary to interpolate and resample bed data to ensure the method can work. The roughness, and the characteristic factors, of each position on the bed is calculated within the variable-size MW at multiple scales. The total number of along-track sample points in the MW is $M=$ $2^{N}$, where $N$ is the window-length exponent. Low-frequency fluctuations are observed on a large scale, and high-frequency fluctuations are observed in the small scale. We therefore calculate the roughness and the characteristic factors at multiple scales, which is analogous to the multi-scale decomposition of the wavelet transform. The scale range we need is equivalent to $10^{2}-10^{4} \mathrm{~m}$ as it includes a variety of glacial bedforms that appear within this interval (e.g. drumlins, U-shaped valleys, crag and tails, etc.) (Ó Cofaigh and others, 2002; Stokes and Clark, 2003).

\subsection{Step 2: calculating the two-parameter roughness of different scales}

The first parameter $\xi_{N}\left(x_{i}\right)$ of the two-parameter roughness index, whose unit is $\mathrm{m}^{2}$ (Li and others, 2010), describes the magnitude of vertical deviations in the bed slope, and is calculated by:

$$
\begin{gathered}
Z_{0}\left(x_{i}\right)=Z\left(x_{i}\right)-\bar{Z} \\
S_{N}(k)=\frac{1}{M} \frac{\left|\operatorname{FFT}\left(Z_{0}\left(x_{i}\right)\right)\right|^{2}}{M / 2} \\
\xi_{N}\left(x_{i}\right)=\int_{k_{1}}^{k_{2}} S_{N}(k) \mathrm{d} k
\end{gathered}
$$

where $x$ corresponds to the location in the bedrock; $x_{i}$ is the position of the point in the variable-size $\mathrm{MW}(1 \leq i \leq M) ; Z\left(x_{i}\right)$ denotes the bed elevation; $\bar{Z}$ is the mean of $Z\left(x_{i}\right)$ in the variablesize MW; $Z_{0}\left(x_{i}\right)$ is the mean-detrended profile; $S_{N}(k)$ is the spectral power density of $Z_{0}\left(x_{i}\right) ; k$ is the angular frequency; and $k_{1}$ is zero and $k_{2}$ is infinity.

The second parameter $\eta_{N}\left(x_{i}\right)$, whose unit is $\mathrm{m}^{2}$ (Li and others, 2010), quantifies the slope frequency of these deviations, and is obtained using the ratio of the first parameter defined in equation (1) to the slope index. The slope index is calculated using the FFT to convert the slope of the bed elevation profile into the average power. We obtain the slope index $\eta_{N_{\mathrm{sl}}}\left(x_{i}\right)$, by:

$$
\begin{gathered}
S_{N_{\mathrm{sl}}}(k)=\frac{1}{M} \frac{\left|\frac{F F T\left(\partial\left(Z_{0}\left(x_{i}\right)\right)\right)}{\partial x_{i}}\right|^{2}}{M / 2} \\
\eta_{N_{\mathrm{sl}}}\left(x_{i}\right)=\int_{k 1}^{k 2} S_{N_{\mathrm{sl}}}(k) \mathrm{d} k
\end{gathered}
$$

where $S_{N_{\mathrm{sl}}}(k)$ is the spectral power density of the slope profile $\frac{\partial\left(Z_{0}\left(x_{i}\right)\right)}{\partial x_{i}}$. Finally, we obtain $\eta_{N}\left(x_{i}\right)$ as follows,

$$
\eta_{N}\left(x_{i}\right)=\frac{1}{M} \frac{\xi_{N}\left(x_{i}\right)}{\eta_{N_{\mathrm{sl}}}\left(x_{i}\right)}
$$

\subsection{Step 3: calculating the weights}

Three characteristic factors are used to estimate the shape of the bed elevation profile: (1) the slopes, (2) the skewness and (3) the coefficient of variation. They are calculated simultaneously with the variable-size MW.

The slopes are usually used to indicate how inclined a curve is, which include the leading and trailing edge steepness. The leading-edge steepness $\operatorname{SL}_{N}^{1}\left(x_{i}\right)$ of the bed elevation $Z\left(x_{i}\right)$ within the variable-size $\mathrm{MW}$ is estimated by:

$$
\operatorname{SL}_{N}^{1}\left(x_{i}\right)=\frac{Z^{1}\left(x_{i}\right)}{x_{i}}
$$

where $Z^{1}\left(x_{i}\right)$ is the leading edge of the bed elevation. Similarly, the trailing edge steepness, denoted as $\operatorname{SL}_{N}^{\mathrm{t}}\left(x_{i}\right)$, is 


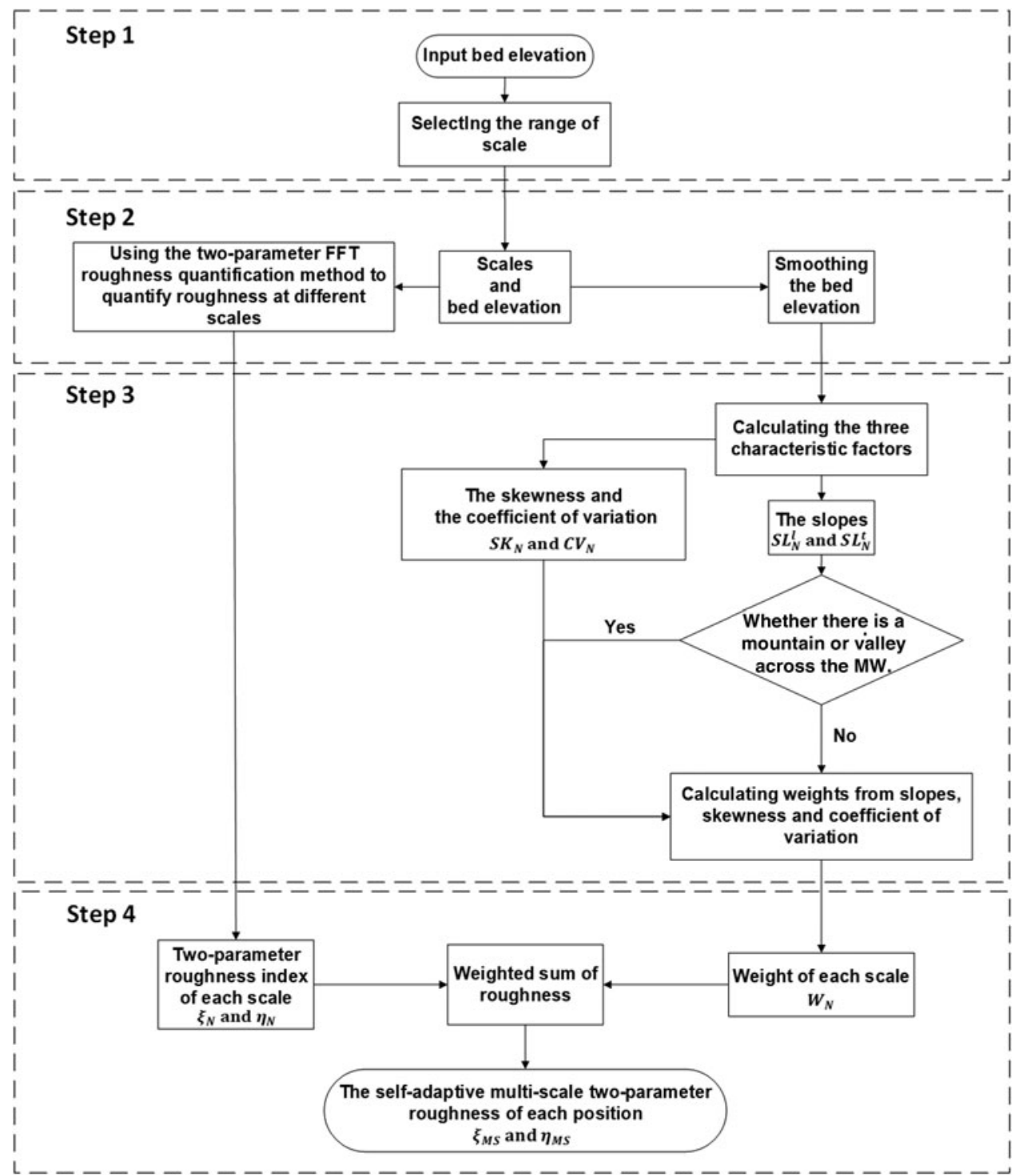

Fig. 1. Flowchart of the self-adaptive two-parameter roughness quantization method. The 'scale' we use in here refers to the horizontal length of the bed that is quantified as roughness. MW is moving window.

calculated by:

$$
\mathrm{SL}_{N}^{\mathrm{t}}\left(x_{i}\right)=\frac{Z^{\mathrm{t}}\left(x_{i}\right)}{x_{i}}
$$

where $Z^{\mathrm{t}}\left(x_{i}\right)$ is the trailing edge. The visualized examples of $\mathrm{SL}_{N}^{1}\left(x_{i}\right)$ and $\mathrm{SL}_{N}^{\mathrm{t}}\left(x_{i}\right)$ are shown in Figure 2. The $\mathrm{SL}_{N}^{1}\left(x_{i}\right)$ and $\mathrm{SL}_{N}^{\mathrm{t}}\left(x_{i}\right)$ quantify the leading and trailing edge steepness, respectively.

In general, skewness, which quantifies the degree of asymmetry of a curve (i.e. the larger the value, the greater the asymmetry) (Moore and Kirkland, 2007), is a measure of the direction and degree of deviation of the bed elevation profile from its center. Firstly, we calculate the expectation value, $E_{N}\left(x_{i}\right)$, and the variance, $D_{N}\left(x_{i}\right)$, of the bed elevation profile as follows:

$$
\begin{gathered}
E_{N}\left(x_{i}\right)=\sum_{i=1}^{M}\left[\frac{Z\left(x_{i}\right)}{\sum_{i=1}^{M} Z\left(x_{i}\right)} x_{i}\right] \\
D_{N}\left(x_{i}\right)=\sum_{i=1}^{M}\left[x_{i}^{2} \frac{Z\left(x_{i}\right)}{\sum_{i=1}^{M} Z\left(x_{i}\right)}\right]-E_{N}\left(x_{0}\right)^{2}
\end{gathered}
$$

where $x_{0}$ denotes the center of the variable-size MW. Next, we calculate the skewness by:

$$
\mathrm{SK}_{N}\left(x_{i}\right)=\left|\sum_{i=1}^{M}\left[\left(\frac{x_{i}-E_{N}\left(x_{0}\right)}{\sqrt{D_{N}\left(x_{0}\right)}}\right)^{3} \frac{Z\left(x_{i}\right)}{\sum_{i=1}^{M} Z\left(x_{i}\right)}\right]\right| .
$$

The coefficient of variation is a measure of the relative dispersion (Yadolah, 2008), and is calculated by:

$$
\mathrm{CV}_{N}\left(x_{i}\right)=\frac{\sqrt{D_{N}\left(x_{0}\right)}}{\left|E_{N}\left(x_{0}\right)\right|}
$$

The visualized examples of $\mathrm{SK}_{N}\left(x_{i}\right)$ and $\mathrm{CV}_{N}\left(x_{i}\right)$ are shown in Figure 2. As we can see in Figure 2, we chose a mountain, two slopes and a valley as examples. The mountain is symmetrical, leading to low values of both $\mathrm{SK}_{N}\left(x_{i}\right)$ and $\mathrm{CV}_{N}\left(x_{i}\right)$. The slopes are asymmetrical and so $\mathrm{SK}_{N}\left(x_{i}\right)$ and $\mathrm{CV}_{N}\left(x_{i}\right)$ will both be high or high $\mathrm{SK}_{N}\left(x_{i}\right)$ and low $\mathrm{CV}_{N}\left(x_{i}\right)$. The valley can lead to low $\operatorname{SK}_{N}\left(x_{i}\right)$ and high $\mathrm{CV}_{N}\left(x_{i}\right)$.

By evaluating the value of $\operatorname{SL}_{N}^{1}\left(x_{i}\right), \operatorname{SL}_{N}^{\mathrm{t}}\left(x_{i}\right), \mathrm{SK}_{N}\left(x_{i}\right)$ and $\mathrm{CV}_{N}\left(x_{i}\right)$ from Eqn (7-12), we can quantify the shape of terrain (Khan and others, 2011; Ilisei and others, 2018), from which we obtain the weight, $W_{N}\left(x_{i}\right)$, of each scale. More detail about how to obtain the weights and how the weights change with the 


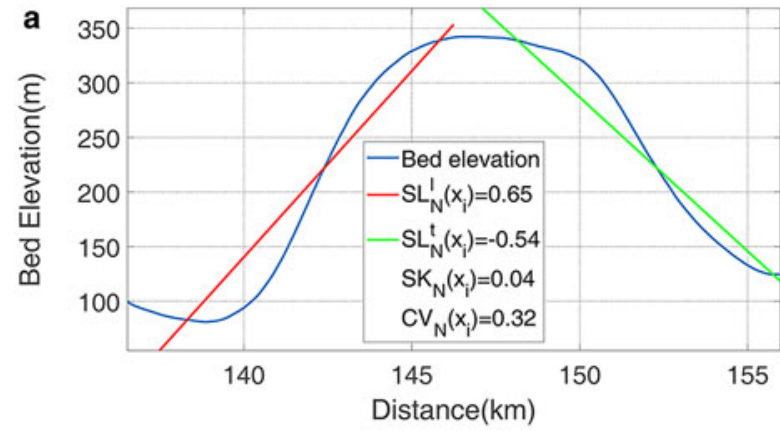

b
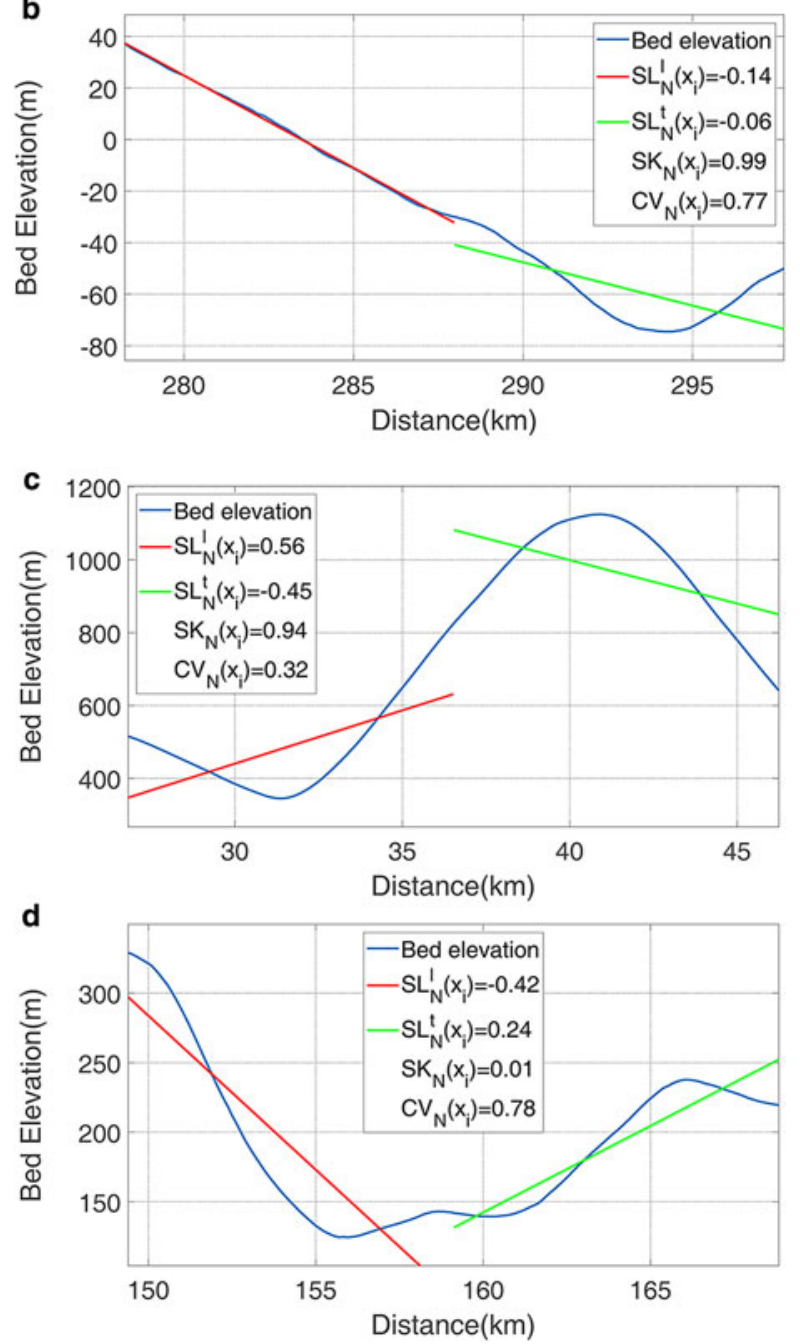

Fig. 2. The leading and trailing edge steepness $\mathrm{SL}_{N}^{1}\left(x_{i}\right)$ and $\mathrm{SL}_{N}^{\mathrm{t}}\left(x_{i}\right)$, the skewness $\mathrm{SK}_{N}\left(x_{i}\right)$ and the coefficient of variation $\mathrm{CV}_{N}\left(x_{i}\right)$ for $N=10$ of four parts of bed elevation profile of TT' in Figure 4. The red line represents $\mathrm{SL}_{N}^{1}\left(x_{i}\right)$ and the green line represents $\mathrm{SL}_{N}^{\mathrm{t}}\left(x_{i}\right)$. (a) From 136 to $156 \mathrm{~km}$ of TT'. (b) From 278 to $298 \mathrm{~km}$ of TT'. (c) From 26 to $46 \mathrm{~km}$ of TT'. (d) From 145 to $165 \mathrm{~km}$ of TT'.

three characteristic factors can be found in Appendix A and Appendix B, respectively.

\subsection{Step 4: calculating the self-adaptive two-parameter roughness index}

Finally, the self-adaptive first and second parameter roughness index, $\xi_{\mathrm{MS}}\left(x_{i}\right)$ and $\eta_{\mathrm{MS}}\left(x_{i}\right)$, are calculated by weighting and summing the roughness of the different scales in Eqn (1) and (3):

$$
\xi_{\mathrm{MS}}\left(x_{i}\right)=\sum_{N=N_{\min }}^{N_{\max }}\left[W_{N}\left(x_{i}\right) \xi_{N}\left(x_{i}\right)\right]
$$
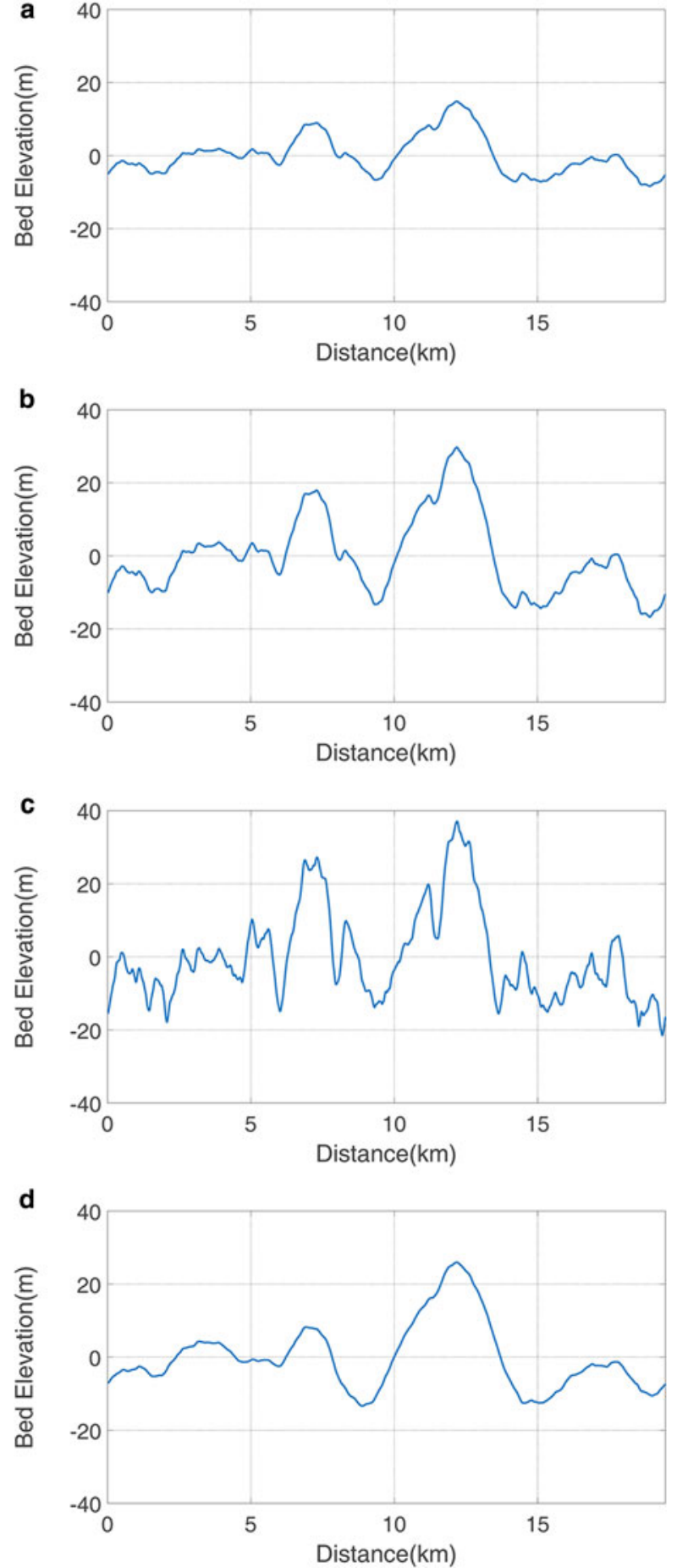

Fig. 3. Random simulated bed elevation profiles with four different roughness. (a) Our self-adaptive first and second parameter roughness index, whose unit is $\mathrm{m}^{2}$, $\xi_{\mathrm{MS}}\left(x_{i}\right)=0.34, \eta_{\mathrm{MS}}\left(x_{i}\right)=1906.1$. (b) $\xi_{\mathrm{MS}}\left(x_{i}\right)=1.35, \eta_{\mathrm{MS}}\left(x_{i}\right)=1906.1$. (c) $\xi_{\mathrm{MS}}\left(x_{i}\right)=1.35$, $\eta_{\mathrm{MS}}\left(x_{i}\right)=455.0$. (d) $\xi_{\mathrm{MS}}\left(x_{i}\right)=1.35, \eta_{\mathrm{MS}}\left(x_{i}\right)=7347.3$.

$$
\eta_{\mathrm{MS}}\left(x_{i}\right)=\sum_{N=N_{\min }}^{N_{\max }}\left[W_{N}\left(x_{i}\right) \eta_{N}\left(x_{i}\right)\right]
$$

where $N_{\min }$ and $N_{\max }$ are the range of $N . \xi_{\mathrm{MS}}\left(x_{i}\right)$ and $\eta_{\mathrm{MS}}\left(x_{i}\right)$ are then the self-adaptive two-parameter roughness index.

\section{Experiments}

\subsection{Simulated bed elevations}

Since the sampling interval of bed elevations that we use later is $\sim 19$ m (Cui and others, 2018), and the variable-size MW should 
a

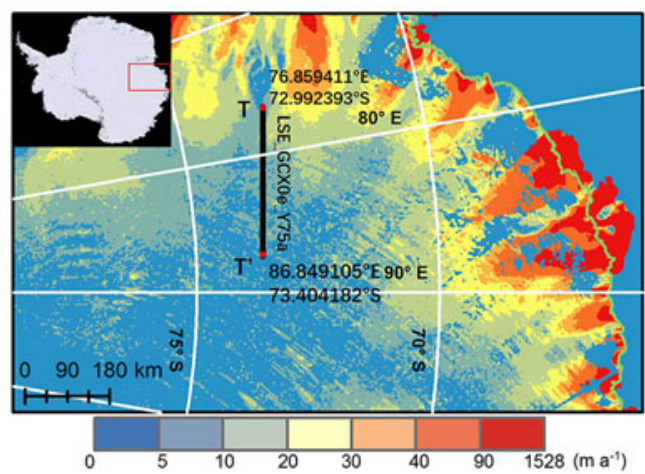

b

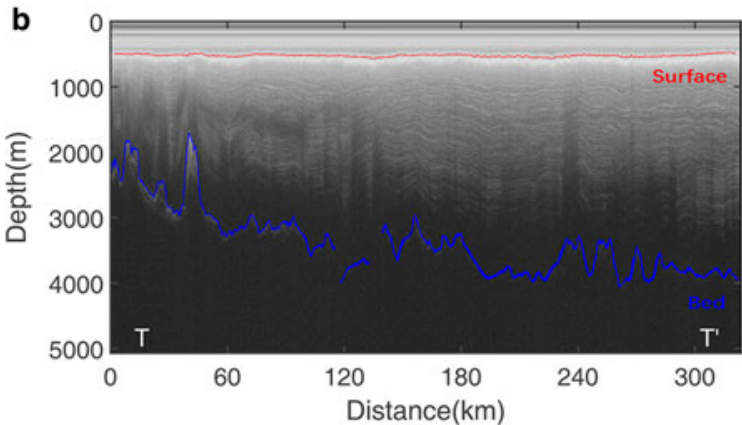

d

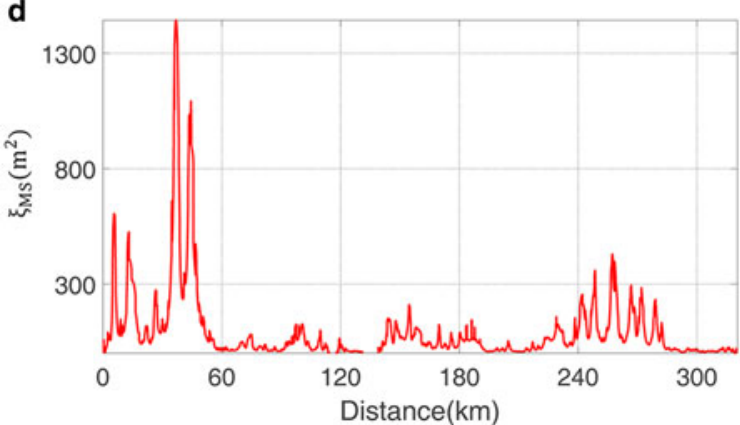

C
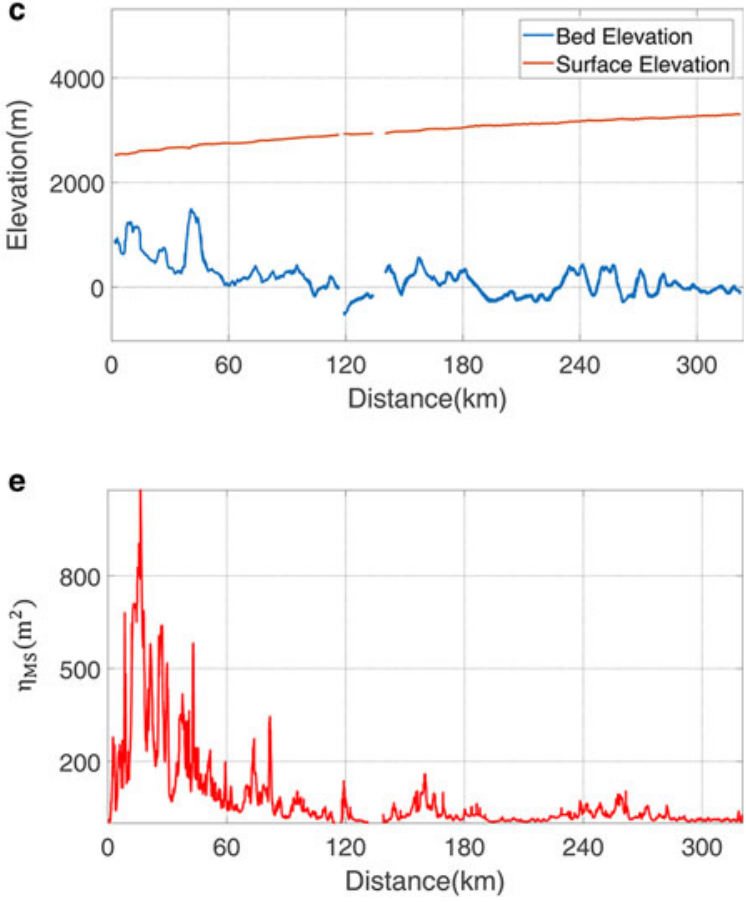

Fig. 4. The profiles of LSE_GCX0e_Y75a (TT'). (a) Ice velocity map and location of TT'. Ice velocity map is from the MEaSUREs InSAR-Based Antarctica Ice Velocity Map, Version 2 (Rignot and others, 2017). Grounding lines are shown in green. (b) Ice-sounding radar profile. (c) Ice-surface elevation and bed elevation. Our selfadaptive first and second parameter roughness index (d) $\xi_{\mathrm{MS}}\left(x_{i}\right)$ and (e) $\eta_{\mathrm{MS}}\left(x_{i}\right)$.

be in the range of $10^{2}-10^{4} \mathrm{~m}$ as mentioned above, we use $5 \leq$ $N \leq 10$ and $M=2^{5}-2^{10}(608-19456 \mathrm{~m})$ to process the real bed elevation dataset. Hence, the simulated bed elevation that we used here has 1024 sample points.

To prove the effectiveness of the algorithm in quantifying roughness, we compare the quantization results of the simulated beds' roughness with a variety of irregularities, described in Figure 3. The simulated bed profiles are generated using a selfcorrelation function (Thomas, 1999; Li and others, 2010). Two controllable inputs, which are standard deviation and autocorrelation length, are used to control the vertical and slope irregularities of the bed, respectively. As we increase the standard deviation but keep the autocorrelation length unchanged, the bed elevation profile transforms from that in Figures $3 a$ to $b$. Accordingly, our self-adaptive first parameter roughness index $\xi_{\mathrm{MS}}\left(x_{i}\right)$ increases and our self-adaptive second parameter roughness index $\eta_{\mathrm{MS}}\left(x_{i}\right)$ is unchanged. On the other hand, if the standard deviation is unchanged but autocorrelation length is increased, the bed elevation profile changes from that in Figures $3 \mathrm{~b}$ to $\mathrm{c}$. In this case, $\xi_{\mathrm{MS}}\left(x_{i}\right)$ is unchanged and $\eta_{\mathrm{MS}}\left(x_{i}\right)$ reduces. Similarly, when the standard deviation is unchanged and autocorrelation length is reduced, which means the bed changes from that in Figures $3 \mathrm{~b}$ to $\mathrm{d}, \xi_{\mathrm{MS}}\left(x_{i}\right)$ is unchanged and $\eta_{\mathrm{MS}}\left(x_{i}\right)$ increases. Theoretically, higher values of the first roughness parameter relate to higher vertical roughnesses; whereas lower values of the second parameter roughness correspond with higher slope roughnesses (Li and others, 2010). This simple analysis shows that the method is working as it should, and can now be applied to more complex, real-world examples. The comparison between the results of our self-adaptive two-parameter method, the previous two-parameter method and the Hurst exponent method in a simulated bed elevation profile can be found in Appendix C.

\subsection{Real bed elevations}

The radar profile used in this study was acquired in CHINARE 33 by the Snow Eagle 601, which is a modified DC-3 aircraft fully equipped with a suite of geophysical instruments. The apparatus of relevance to this paper is the airborne ice sounding radar, functionally similar with the High Capability Airborne Radar System (HiCARS), which uses a double flat-plate dipole antenna with a peak power of $8 \mathrm{~kW}$ and a center frequency of $60 \mathrm{MHz}$. The radar can penetrate Antarctic ice to a depth of more than $3 \mathrm{~km}$, 
and can measure internal reflection horizons with a high detection resolution (Cui and others, 2018).

The radar data were processed using along-track coherent stacking, pulse compression and along-track incoherent stacking. The data resolution in the along-track direction is $\sim 19 \mathrm{~m}$ after the process of interpolation and resampling, and the depth resolution is $\sim 10 \mathrm{~m}$ in air and $\sim 5.6 \mathrm{~m}$ in ice (Cui and others, 2018). The bed-ice interfaces were traced and digitized by a semi-automatic program, using the manually picked lower and upper boundaries of the bed interface as a constraint on automatic bed interface picking (Cui and others, 2020). The program was also used to process the former ICECAP data from the Aurora and Wilkes subglacial basins (Blankenship and others, 2016, 2017).

In this paper, we have analyzed the radar profile 'LSE_GCX0e_Y75a', which is referred to as TT' and has a length of $323.9 \mathrm{~km}$. The radar profile is shown in Figure $4 \mathrm{~b}$, and its bed elevation and ice-surface are shown in Figure 4c. The roughness results from our algorithm are shown in Figures $4 \mathrm{~d}$ and e. The radar profile is located between $\sim 77^{\circ} \mathrm{E}$ and $\sim 87^{\circ} \mathrm{E}$ in an approximate west-east direction, covering a region with low ice-flow speed,

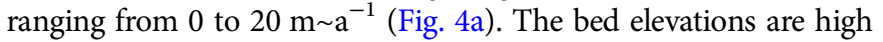
between 0 and $60 \mathrm{~km}$, and elsewhere vary closer to the sea level with a relatively low amplitude of several hundred meters. An obvious mountain occurs between $\sim 35$ and $55 \mathrm{~km}$, and two relatively smooth areas appear between $\sim 190$ and $\sim 230 \mathrm{~km}$ and between $\sim 280 \mathrm{~km}$ and the end of the profile.

\subsection{Comparison of results}

\subsubsection{The Hurst exponent}

The statistical methods used to calculate the Hurst exponent $(H)$, and thus to quantify the self-affine scaling behavior, are well established in the literature (Malinverno, 1990; Shepard and others, 2001; Kulatilake and others, 1998; Orosei and others, 2003). A feature of terrain with a higher $H$ is that it tends to appear relatively rough at larger length scales (low frequencies) and smooth at smaller length scales (high frequencies). A feature of lower $H$ terrain is that it tends to have similar roughness across different length scales (Jordan and others, 2017). We used the rms height, $R(L)$, to extract the Hurst exponent:

$$
R(L)=\sqrt{\frac{1}{P-1} \sum_{i=1}^{L}\left[Z\left(x_{i}\right)-\bar{Z}\right]^{2}}
$$

where $P$ is the number of sample points within the profile window; and $L$ is the length of the profile window. We then extract the Hurst exponent $H$ by the rms height as follows:

$$
R(L)=R\left(L_{0}\right)\left(\frac{L}{L_{0}}\right)^{H}
$$

where $L_{0}$ is a reference profile length. As $L$ increases, $R(L)$ also increases, as they have a linear relationship. Thus, the Hurst exponent $H$ is the slope of $L$ and $R(L)$. The Hurst exponent is a multi-scale standardized result that can be compared with the rms height, or slopes of different surfaces, as measured by different tools at similar scales (Shepard and others, 2001).

\subsubsection{Roughness comparisons}

Profile TT' crosses the Kronshtadtskiy Glacier. The first $50 \mathrm{~km}$ is characterized by high $\xi_{\mathrm{MS}}\left(x_{i}\right)$ and high $\eta_{\mathrm{MS}}\left(x_{i}\right)$, while the other sections are mainly characterized by low $\xi_{\mathrm{MS}}\left(x_{i}\right)$ and low $\eta_{\mathrm{MS}}\left(x_{i}\right)$ roughness (Figs $4 \mathrm{~d}$ and e). We now focus on the
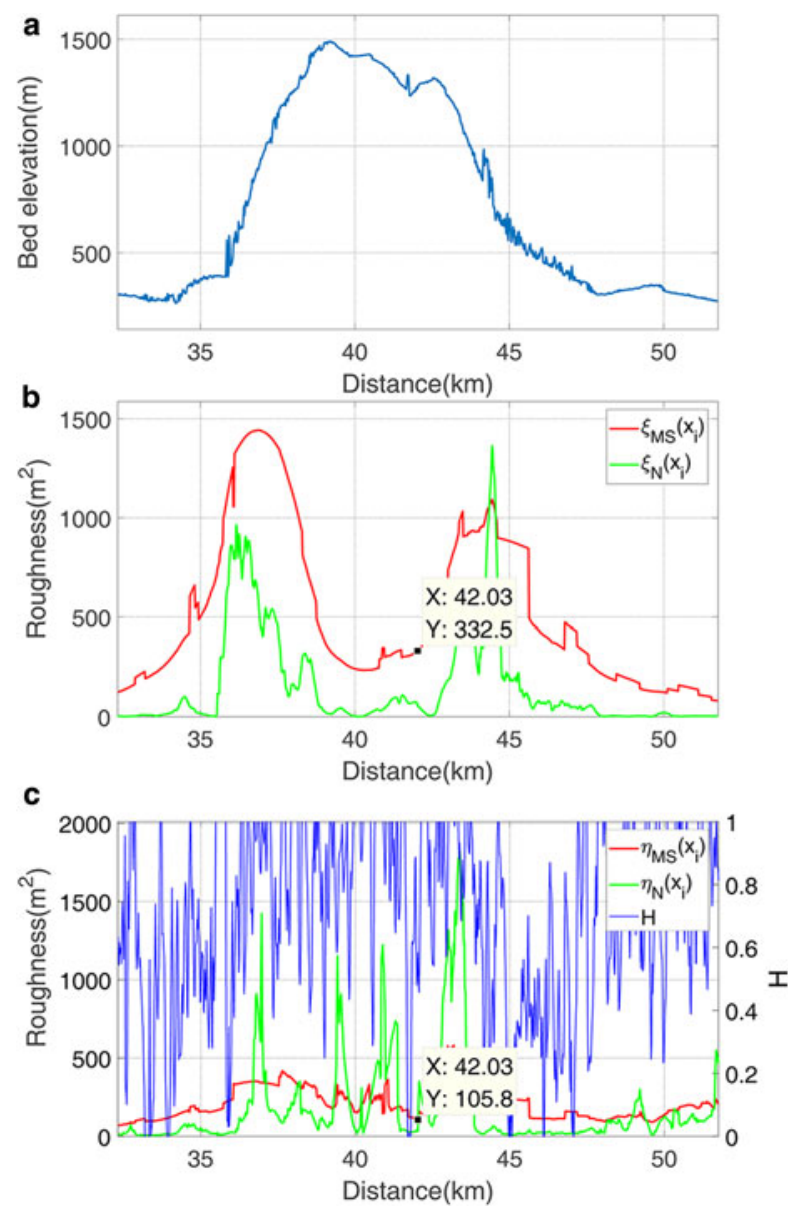

Fig. 5. A part of roughness of profile TT' (from 32 to $52 \mathrm{~km}$ ). The marked points locate in the center of the profile. (a) The bed elevation profile. (b) Our self-adaptive first parameter roughness index $\xi_{\mathrm{MS}}\left(x_{i}\right)$ and Li's first parameter roughness index $\xi_{N}\left(x_{i}\right)$. (c) Our self-adaptive second parameter roughness index $\eta_{\mathrm{MS}}\left(x_{i}\right)$, Li's second parameter roughness index $\eta_{N}\left(x_{i}\right)$ and the Hurst exponent $H$. The $\xi_{N}\left(x_{i}\right)$ and $\eta_{N}\left(x_{i}\right)$ are calculated when $N=5$.

mountain at about $40 \mathrm{~km}$ (Fig. 5). Comparing the roughness results of the profile at this place, we can see that $\xi_{\mathrm{MS}}\left(x_{i}\right)$ and $\xi_{N}\left(x_{i}\right)$ each have peaks. But $\xi_{N}\left(x_{i}\right)$ shows very low values from 39 to $42 \mathrm{~km}$, and $\xi_{\mathrm{MS}}\left(x_{i}\right)$ shows high values representing the span of the mountain. $\eta_{\mathrm{MS}}\left(x_{i}\right)$ has several very low peaks, indicative of high roughness, in contrast to $\eta_{N}\left(x_{i}\right)$. The trend of Hurst exponent, $\eta_{\mathrm{MS}}\left(x_{i}\right)$ and $\eta_{N}\left(x_{i}\right)$ is roughly the same, as described in Figure $5 \mathrm{c}$.

Li et al. (2010)'s first and second parameter roughness index $\xi_{N}\left(x_{i}\right)$ and $\eta_{N}\left(x_{i}\right)$ are sensitive to the MW size. To prove this, we calculate $\xi_{N}\left(x_{i}\right)=55.1$ and $\eta_{N}\left(x_{i}\right)=32.9$ at $N=5$ in the central position of the profile, as shown in Figure 5. We then calculate $\xi_{N}\left(x_{i}\right)$ and $\eta_{N}\left(x_{i}\right)$ in same position while increasing $N$, revealing differences in both $\xi_{N}\left(x_{i}\right)$ and $\eta_{N}\left(x_{i}\right)$ (i.e. $\xi_{N}\left(x_{i}\right)=30.1$ and $\eta_{N}\left(x_{i}\right)=22.9$ at $N=6 ; \xi_{N}\left(x_{i}\right)=66.0$ and $\eta_{N}\left(x_{i}\right)=86.3$ at $N=7$; $\xi_{N}\left(x_{i}\right)=431.9$ and $\eta_{N}\left(x_{i}\right)=123.4$ at $N=8 ; \xi_{N}\left(x_{i}\right)=800.4$ and $\eta_{N}\left(x_{i}\right)=195.2$ at $N=9$; and $\xi_{N}\left(x_{i}\right)=611.4$ and $\eta_{N}\left(x_{i}\right)=174.0$ at $N=10)$. In contrast, our self-adaptive first and second parameter roughness index $\xi_{M S}\left(x_{i}\right)=332.5$ and $\eta_{\mathrm{MS}}\left(x_{i}\right)=105.8$ are stable across the scale range, as shown in Figures $5 \mathrm{~b}$ and c. The unit of $\xi_{N}\left(x_{i}\right), \eta_{N}\left(x_{i}\right), \xi_{\mathrm{MS}}\left(x_{i}\right)$ and $\eta_{\mathrm{MS}}\left(x_{i}\right)$ is $\mathrm{m}^{2}(\mathrm{Li}$ and others, 2010).

Through the last $76 \mathrm{~km}$ of TT', we can see several mountain peaks and valleys (Fig. 6). By comparing the $\eta_{\mathrm{MS}}\left(x_{i}\right)$ and $H$ of the profile in this place, we can see that $\eta_{\mathrm{MS}}\left(x_{i}\right)$ has several very low peaks, indicative of high roughness, but the Hurst exponent has too many peaks to resolve (Fig. $6 \mathrm{c}$ ). 

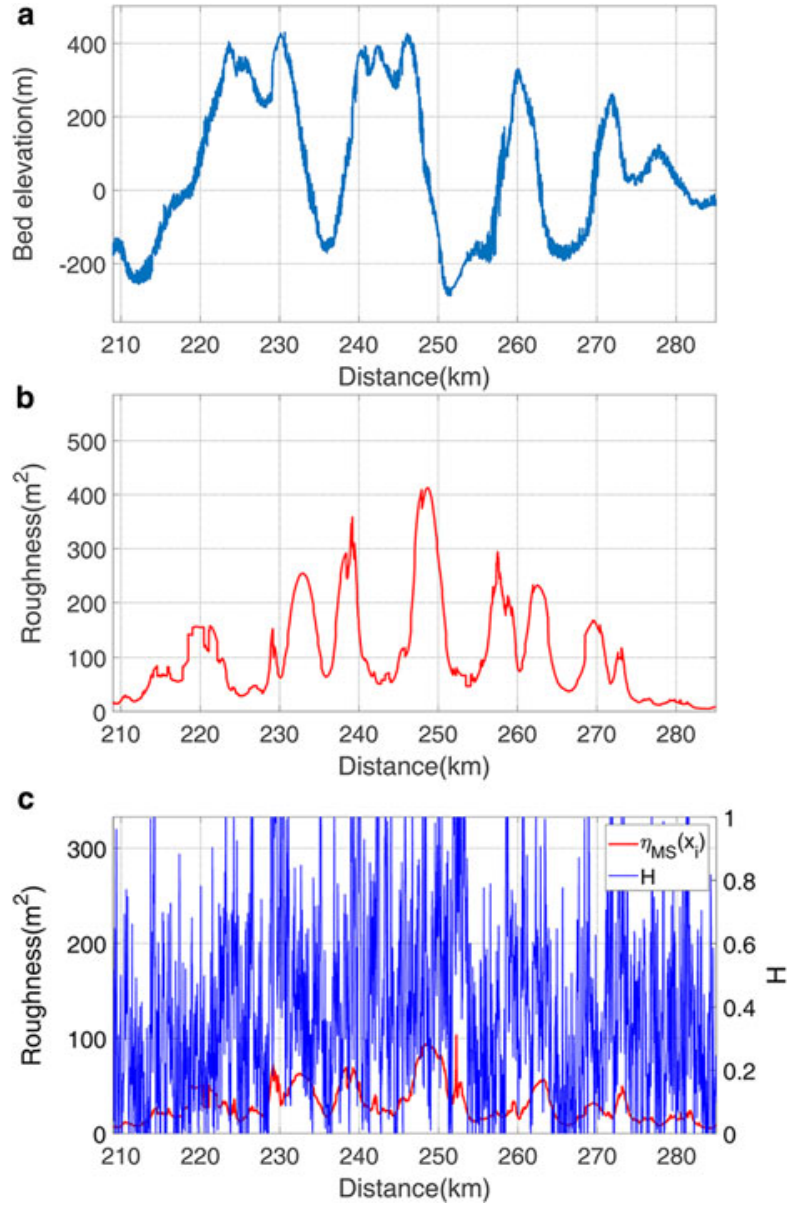

Fig. 6. A part of roughness of profile TT' (from 209 to $285 \mathrm{~km}$ ). (a) The bed elevation profile. (b) The roughness index $\xi_{\mathrm{MS}}\left(x_{i}\right)$. (c) The roughness index $\eta_{\mathrm{MS}}\left(x_{i}\right)$ and the Hurst exponent $H$.

\section{Conclusions}

We describe a new method to determine subglacial topographic roughness, called the 'self-adaptive two-parameter roughness quantization' method. The algorithm is based on the twoparameter roughness quantization method and is analogous to a wavelet transform. According to the weights calculated from three characteristic factors, the new algorithm can determine the scale needed to quantify the roughness at any position. This eliminates the problem of a fixed-size MW of measurements being unable to cope with roughness at multiple scales.

We use simulated bed elevations to test the new algorithm, demonstrating hypothetically the effectiveness of the new algorithm in quantifying roughness. In cases where real bed elevations are used, we show that the algorithm can achieve a better characterization of roughness than the previous twoparameter method. Comparisons between the results of our selfadaptive two-parameter method, the previous two-parameter method and the Hurst exponent method show the advantage of our approach in capturing different scales of terrain span and demonstrate the effectiveness of the new algorithm in quantifying bed roughness.

This method provides an improved tool for quantifying the roughness of the subglacial environment from a multi-scale perspective, especially in the analysis of complex subglacial topography. The new method offers a means by which multi-scale roughness can be quantified at a continental scale. Such a product would have significant glaciological applications, especially in distinguishing between erosional and depositional landscapes. The method could be applied to higher along-track resolution data if it is available in the future for evaluating the magnitude and distribution of basal sliding at the meter scale. The method works particularly well over subglacial landscapes with horizontal lengths greater than the length of a traditional fixed-size MW (e.g. mountains and valleys), resolving the roughness in all places. It also works well in landscapes that have notable roughness at a scale less than a fixed-size MW, as it is able to incorporate the fine-scale roughness within the wider terrain.

The code/routines of the self-adaptive two-parameter roughness quantization method will be freely available under requests from any researchers. We hope the new method can be extensively used by the community to characterize subglacial roughness in future.

Acknowledgements. This work was supported by the National Natural Science Foundation of China (Nos. 41941006, 41606219, 41776186), the National Key R\&D Program of China (2019YFC1509102), the Scientific Research Project of Beijing Educational Committee (No. KM201910005027) and the Rixin Foundation of Beijin University of Technology. M.J.S. was supported by a British Council 'Global Innovation Initiative' award. We also thank the anonymous reviewers for their positive comments and suggestions for improving this paper and editors for editing this paper.

\section{References}

Blankenship D and 12 others (2016) IceBridge HiCARS 1 L2 geolocated ice thickness, version 1. NASA Distributed Active Archive Center (DAAC) at the National Snow and Ice Data Center (NSIDC) (doi: 10.5067/ F5FGUT9F5089).

Blankenship D and 12 others (2017) IceBridge HiCARS 2 L2 geolocated ice thickness, version 1. NASA Distributed Active Archive Center (DAAC) at the National Snow and Ice Data Center (NSIDC) (doi: 10.5067/ 9EBR2T0VXUDG).

Boggess A and Narcowich FJ (2015) A First Course in Wavelets with Fourier Analysis. Hoboken, NJ: John Wiley \& Sons.

Cooper MA and 5 others (2019) Subglacial roughness of the Greenland Ice Sheet: relationship with contemporary ice velocity and geology. Cryosphere 13(11), 3093-3115. doi: 10.5194/tc-13-3093-2019.

Cui $\mathrm{X}$ and 7 others (2018) The first fixed-wing aircraft for Chinese Antarctic Expeditions: Airframe, modifications, scientific instrumentation and applications. Journal of Environmental and Engineering Geophysics 23(1), 1-13. doi: 10.2113/JEEG23.1.1.

Cui X and 15 others (2020) Bed topography of Princess Elizabeth Land in East Antarctica. Earth System Science Data 12(4), 2765-2774. doi: 10.5194/essd-12-2765-2020.

Eisen O, Winter A, Steinhage D, Kleiner T and Humbert A (2020) Basal roughness of the East Antarctic Ice Sheet in relation to flow speed and basal thermal state. Annals of Glaciology 61(81), 162-175. doi: 10.1017/ aog.2020.47.

Goff JA, Powell EM, Young DA and Blankenship DD (2014) Conditional simulation of Thwaites Glacier (Antarctica) bed topography for flow models: incorporating inhomogeneous statistics and channelized morphology. Journal of Glaciology 60(222), 635-646. doi: 10.3189/2014JoG13J200.

Grima C, Schroeder DM, Blankenship DD and Young DA (2014) Planetary landing-zone reconnaissance using ice-penetrating radar data: Concept validation in Antarctica. Planetary and Space Science 103, 191-204. doi: 10.1016/j.pss.2014.07.018.

Hubbard B and Hubbard A (1998) Bedrock surface roughness and the distribution of subglacially precipitated carbonate deposits: implications for formation at glacier de Tsanfleuron, Switzerland. Earth Surface Processes and Landforms 23(3), 261-270. doi: 10.1002/(SICI)1096-9837 (199803)23:3<261::AID-ESP848>3.0.CO;2-5

Hubbard B, Siegert MJ and McCarroll D (2000) Spectral roughness of glaciated bedrock geomorphic surfaces: implications for glacier sliding. Journal of Geophysical Research-Solid Earth 105(B9), 21295-21304. doi: 10.1029/ 2000JB900162.

Ilisei AM, Khodadadzadeh M, Ferro A and Bruzzone L (2018) An automatic method for subglacial lake detection in ice sheet radar sounder data. IEEE 
Transactions on Geoscience and Remote Sensing 57(6), 3252-3270. doi: 10. 1109/TGRS.2018.2882911.

Jordan TM and 6 others (2017) Self-affine subglacial roughness: consequences for radar scattering and basal water discrimination in northern Greenland. Cryosphere 11(3), 1247-1264. doi: 10.5194/tc-11-1247-2017.

Joughin IR, Kwok R and Fahnestock MA (1998) Interferometric estimation of three-dimensional ice-flow using ascending and descending passes. IEEE Transactions on Geoscience and Remote Sensing 36(1), 25-37. doi: 10.1109/ 36.655315.

Khan MS, Aleem M and Shah AA (2011) Theoretical Analysis of Weighted Exponential Models. Proceedings of the 2011 International Conference on Applied, Numerical and Computational Mathematics, and Proceedings of the 2011 International Conference on Computers, Digital Communications and Computing. Stevens Point, WI: World Scientific and Engineering Academy and Society (WSEAS).

Kulatilake PHSW, Um J and Pan G (1998) Requirements for accurate quantification of self-affine roughness using the variogram method. International Journal of Solids and Structures 35(31-32), 4167-4189. doi: 10.1016/S0020-7683(97)00308-9.

Li X and 7 others (2010) Characterization of subglacial landscapes by a two-parameter roughness index. Journal of Glaciology 56(199), 831-836. doi: $10.3189 / 002214310794457326$.

MacGregor JA and 7 others (2013) Weak bed control of the eastern shear margin of Thwaites Glacier, West Antarctica. Journal of Glaciology 59 (217), 900-912. doi: 10.3189/2013JoG13J050.

Mackie EJ, Schroeder DM, Caers J, Siegfried MR and Scheidt C (2020) Antarctic topographic realizations and geostatistical modeling used to map subglacial lakes. Journal of Geophysical Research-Earth Surface 125 (3), e2019JF005420 doi: 10.1029/2019JF005420.

Malinverno A (1990) A simple method to estimate the fractal dimension of self-affine series. Geophysical Research Letters 17(11), 1953-1956. doi: 10.1029/GL017i011p01953.

Martinez OS, Salgado JAM, Cruz DM, Chavarin JU and Bustos ES (2013) Rough surfaces profiles and speckle patterns analysis by hurst exponent method. Journal of Material Science and Engineering B 3(12), 759-766. doi: 10.17265/2161-6221/2013.12.002.

Moore DS and Kirkland S (2007) The basic practice of statistics. New York: WH Freeman, 2

Ó Cofaigh C, Pudsey CJ, Dowdeswell JA and Morris P (2002) Evolution of subglacial bedforms along a paleo-ice stream, Antarctic Peninsula continental shelf. Geophysical Research Letters 29(8), 41-1. doi: 10.1029/ 2001GL014488.

Orosei R and 6 others (2003) Self-affine behavior of Martian topography at kilometer scale from mars orbiter laser altimeter data. Journal of Geophysical Research-Planets 108(E4), 8023. doi: 10.1029/2002JE001883.

Paterson WSB (1994) The physics of glaciers. 3rd edn, ButterworthHeinemann, Oxford.

Rignot E, Mouginot J and Scheuchl B (2017) MEaSUREs InSAR-Based Antarctica Ice Velocity Map, Version 2. NASA DAAC at the National Snow and Ice Data Center, Boulder, CO doi: 10.5067/ D7GK8F5J8M8R.

Rippin DM, Bamber JL, Siegert MJ, Vaughan DG and Corr HFJ (2006) Basal conditions beneath enhanced-flow tributaries of slessor glacier, east antarctica. Journal of Glaciology 52(179), 481-490. doi: 10.3189/ 172756506781828467.

Schoof C (2002) Basal perturbations under ice streams: form drag and surface expression. Journal of Glaciology 48(162), 407-416. doi: 10.3189/ 172756502781831269.

Schroeder DM, Blankenship DD and Young DA (2013) Evidence for a water system transition beneath Thwaites Glacier, West Antarctica. Proceedings of the National Academy of Sciences of the USA 110(30), 12225-12228. doi: 10.1073/pnas.1302828110.

Shepard MK and 5 others (2001) The roughness of natural terrain: a planetary and remote sensing perspective. Journal of Geophysical Research-Planets 106(E12), 32777-32795. doi: 10.1029/2000JE001429.

Stokes CR and Clark CD (2003) Laurentide ice streaming on the canadian shield: A conflict with the soft-bedded ice stream paradigm?. Geology 31(4), 347-350. doi: 10.1130/0091-7613(2003)031<0347:LISOTC<2.0.CO;2.

Taylor J, Siegert MJ, Payne AJ and Hubbard B (2004) Regional-scale bed roughness beneath ice masses: Measurement and analysis. Computers \& Geosciences 30(8), 899-908. doi: 10.1016/j.cageo.2004.06.007.

Thomas TR (1999) Rough surfaces. London: Imperial college press, 278
Yadolah D (2008) Coefficient of Variation. Springer, New York, New York, NY, ISBN 978-0-387-32833-1, doi: 10.1007/978-0-387-32833-1_65.

\section{Appendix A. Calculating the weight}

By evaluating the value of $\mathrm{SL}_{N}^{1}\left(x_{i}\right), \mathrm{SL}_{N}^{\mathrm{t}}\left(x_{i}\right), \mathrm{SK}_{N}\left(x_{i}\right)$ and $\mathrm{CV}_{N}\left(x_{i}\right)$ from Eqn (9-12), we can quantify the shape of terrain, from which we obtain the weight, $W_{N}\left(x_{i}\right)$, of each scale as follows,

$$
\begin{aligned}
W_{N}\left(x_{i}\right)= & {\left[\operatorname{sgn}\left(\operatorname{SL}_{N}^{1}\left(x_{i}\right)\right) \oplus \operatorname{sgn}\left(\operatorname{SL}_{N}^{\mathrm{t}}\left(x_{i}\right)\right)\right] } \\
& \times\left[\alpha\left(x_{i}\right) \frac{1 \mathrm{SK}_{N}\left(x_{i}\right)}{\sum_{N}^{N_{\text {valid }}} 1 \operatorname{SK}_{N}\left(x_{i}\right)}\right. \\
& \left.+\left(1-\alpha\left(x_{i}\right)\right) \frac{1 \mathrm{CV}_{N}\left(x_{i}\right)}{\sum_{N}^{N_{\text {valid }}} 1 \mathrm{CV}_{N}\left(x_{i}\right)}\right]
\end{aligned}
$$

where $N_{\text {valid }}$ are the scales at $\left[\operatorname{sgn}\left(\operatorname{SL}_{N_{\text {valid }}}^{l}\left(x_{i}\right)\right) \oplus \operatorname{sgn}\left(\operatorname{SL}_{N_{\text {valid }}}^{t}\left(x_{i}\right)\right)\right]=1 ; \operatorname{sgn}(\cdot)$ is the sign function that if $\cdot>0$ return 1 and if $\cdot<0$ return $-1 ; \oplus$ is the exclusive or (xor) function. The $\alpha\left(x_{i}\right)$ is the parameter for adjusting the influence of $\mathrm{SK}_{N}\left(x_{i}\right)$ and $\mathrm{CV}_{N}\left(x_{i}\right)$ on the weight distribution, which is calculated by:

$$
\alpha\left(x_{i}\right)=\frac{\sigma\left(\mathrm{SK}_{N}\left(x_{i}\right)\right)}{\sigma\left(\mathrm{SK}_{N}\left(x_{i}\right)\right)+\sigma\left(\mathrm{CV}_{N}\left(x_{i}\right)\right)}
$$

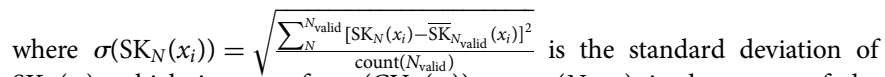
$\mathrm{SK}_{N}\left(x_{i}\right)$, which is same for $\sigma\left(\mathrm{CV}_{N}\left(x_{i}\right)\right)$; $\operatorname{count}\left(N_{\text {valid }}\right)$ is the count of the $N_{\text {valid }} ; \overline{\mathrm{SK}}_{N_{\text {valid }}}\left(x_{i}\right)$ is the mean of $\mathrm{SK}_{N}\left(x_{i}\right)$ at $N=N_{\text {valid. }}$. The greater the measure of dispersion of $\mathrm{SK}_{N}\left(x_{i}\right)$, the greater the $\alpha\left(x_{i}\right)$, which is same for $\mathrm{CV}_{N}\left(x_{i}\right)$ and $1-\alpha\left(x_{i}\right)$.

\section{Appendix B. Three characteristic factors and the associated weights}

The changes in the weight $W_{N}\left(x_{i}\right)$ with the skewness $\operatorname{SK}_{N}\left(x_{i}\right)$ and the coefficient of variation $\mathrm{CV}_{N}\left(x_{i}\right)$ at $N=10$ are shown in Figure 7. To make it easier to understand, we discard the $\mathrm{SK}_{N}\left(x_{i}\right)$ and $\mathrm{CV}_{N}\left(x_{i}\right)$ at $\left[\operatorname{sgn}\left(\mathrm{SL}_{N}^{1}\left(x_{i}\right)\right) \oplus \operatorname{sgn}\left(\operatorname{SL}_{N}^{\mathrm{t}}\left(x_{i}\right)\right)\right]=0$.

When other conditions remain unchanged, both low values of $\operatorname{SK}_{N}\left(x_{i}\right)$ and $\mathrm{CV}_{N}\left(x_{i}\right)$ will make the $W_{N}\left(x_{i}\right)$ high like the part from 41 to $42 \mathrm{~km}$. The $W_{N}\left(x_{i}\right)$ at $N=10$ is also influenced by $\operatorname{SK}_{N}\left(x_{i}\right), \operatorname{CV}_{N}\left(x_{i}\right)$ and $\left[\operatorname{sgn}\left(\operatorname{SL}_{N}^{1}\left(x_{i}\right)\right) \oplus \operatorname{sgn}\left(\operatorname{SL}_{N}^{\mathrm{t}}\left(x_{i}\right)\right)\right]$ at $N \neq 10$ like the part from 36 to $37 \mathrm{~km}$ that $\left[\operatorname{sgn}\left(\mathrm{SL}_{N}^{\mathrm{l}}\left(x_{i}\right)\right) \oplus \operatorname{sgn}\left(\mathrm{SL}_{N}^{\mathrm{t}}\left(x_{i}\right)\right)\right]=0$ at $N=5-9$.

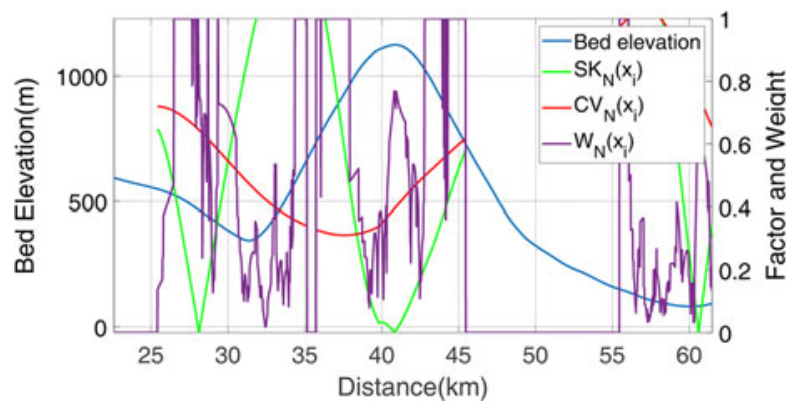

Fig. 7. The changes in the weight $W_{N}\left(x_{i}\right)$ with the skewness $\mathrm{SK}_{N}\left(x_{i}\right)$ and the coefficient of variation $\mathrm{CV}_{N}\left(x_{i}\right)$ at $N=10$. The example is located in a part of profile TT' (from 22 to $62 \mathrm{~km}$ ).

\section{Appendix C. Comparison of roughness results in a simulated bed elevation profile}

We compare the results of our self-adaptive two-parameter method with the results of the previous two-parameter method and the Hurst exponent method in a simulated bed elevation profile shown in Figure 8, which demonstrate the Li's first and second parameter roughness index $\xi_{N}\left(x_{i}\right)$ and $\eta_{N}\left(x_{i}\right)$ are sensitive to the scale and the Hurst exponent $\mathrm{H}$ has the shortcoming of rapid fluctuations. In contrast, our self-adaptive first and second parameter roughness index $\xi_{\mathrm{MS}}\left(x_{i}\right)$ and $\eta_{\mathrm{MS}}\left(x_{i}\right)$ are stable across the scale range. 

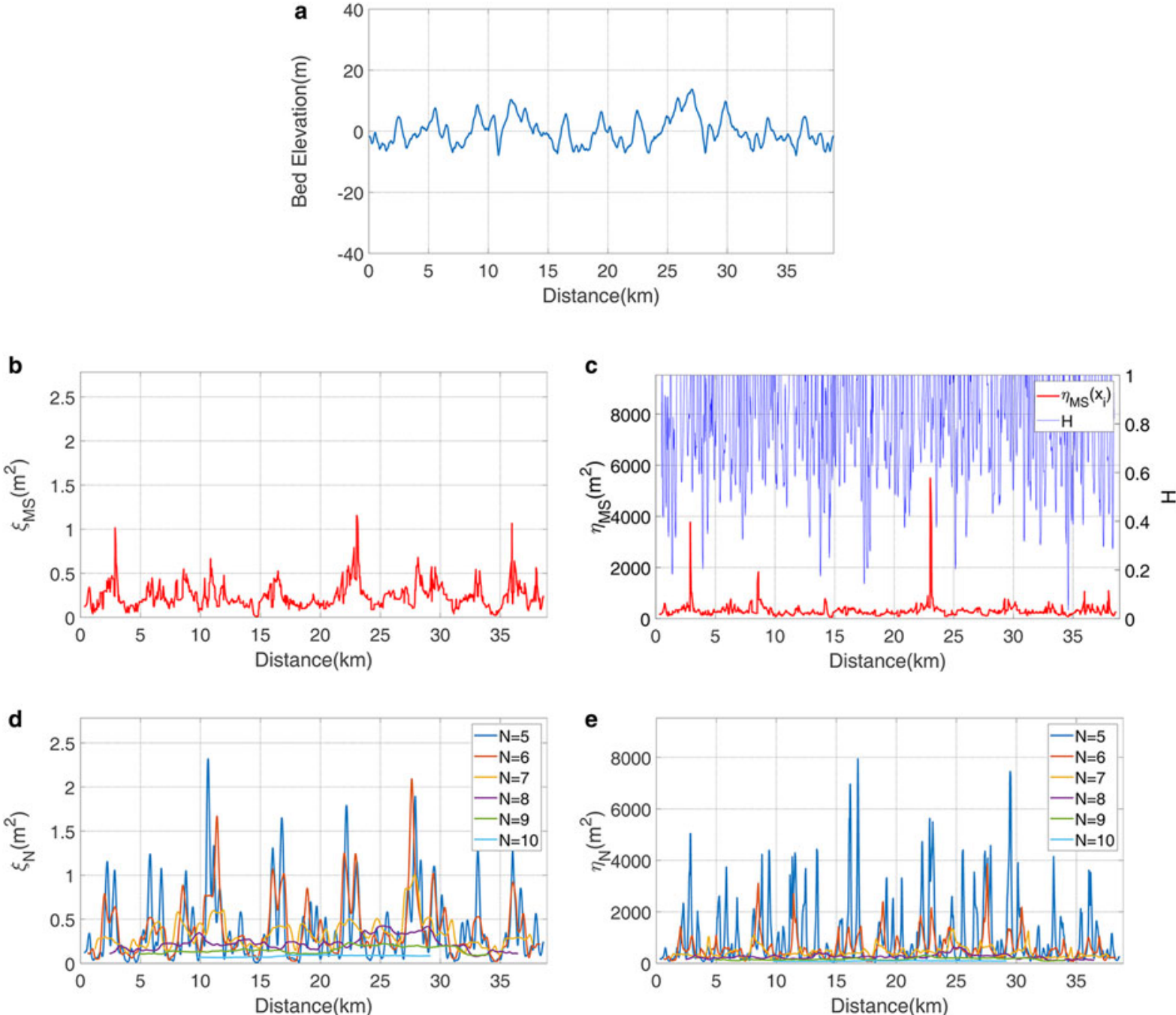

Fig. 8. The roughnesses of simulated bed elevation profile. (a) Random simulated bed elevation profile about $40 \mathrm{~km}$ long; our self-adaptive first and second parameter roughness index (b) $\xi_{\mathrm{MS}}\left(x_{i}\right)$, (c) $\eta_{\mathrm{MS}}\left(x_{i}\right)$ and Hurst exponent $H$; Li's first and second parameter roughness index (d) $\xi_{N}\left(x_{i}\right)$, and (e) $\eta_{N}\left(x_{i}\right)$. 